\title{
Juvenile polyposis of the stomach: clinicopathological features and its malignant potential
}

Kazuoki Hizawa, Mitsuo Iida, Takashi Yao, Kunihiko Aoyagi, Masatoshi Fujishima

\begin{abstract}
Aims-To clarify a clinical entity of juvenile polyposis of the stomach compared with generalised juvenile gastrointestinal polyposis.

Methods-The clinicopathological features of juvenile polyposis dominantly involving the stomach at initial presentation were reviewed in 12 patients (three new patients and nine from the literature). These were compared with 29 cases of generalised juvenile gastrointestinal polyposis.
\end{abstract}

Results-There were three men and nine women with juvenile polyposis of the stomach, aged 10-63 years. Hypoproteinaemia was present in nine patients, anaemia in seven, and a family history of intestinal polyposis in seven. No patient presented with a congenital abnormality. During the observation period, two patients developed colonic juvenile polyps. Gastric polyps invariably affected the antrum and extended to the fundus, eventually becoming more numerous, larger, and more pedunculated. Ten patients required gastrectomy for associated malignancy or uncontrolled protein losing gastropathy. Histological examinations of the resected specimens demonstrated neoplastic tissue arising from juvenile polyps in four of the 12 patients. Atypism in these mixed polyps varied from adenoma to well or moderately differentiated adenocarcinoma.

Conclusions-Juvenile polyposis of the stomach has malignant potential, and may be a separate entity from generalised juvenile gastrointestinal polyposis. (7 Clin Pathol 1997;50:771-774)

Keywords: juvenile polyposis; gastric polyp; gastric cancer; generalised juvenile gastrointestinal polyposis

Second Department of Pathology, Faculty of Medicine, Kyushu University, Fukuoka, Japan

T Yao

Correspondence to: Dr Hizawa, Second Department of Internal Medicine, Faculty of Medicine, Kyushu

University, Maidashi 3-1-1,

Higashi-ku, Fukuoka 812-82, Japan.

Accepted for publication 12 June 1997 cases that corresponded to this condition. ${ }^{36-12}$ Because of its rarity, it is unclear whether JPS is an independent clinical entity distinct from GJGP. We describe three new patients with JPS and review the literature to elucidate the relevant clinicopathological features.

\section{Methods}

We have diagnosed three patients with JPS in Kyushu University since 1975 . The diagnosis for JPS is as follows: (1) patients undergo gastroduodenoscopy, sigmoidoscopy, and double contrast radiography of the gastrointestinal tract, including the small intestine; (2) no initial intestinal lesions are identified except for numerous gastric polyps; (3) histological examination of the gastric lesions obtained by endoscopic or surgical resection demonstrates typical features of juvenile polyps-dilated cystic glands lined by tall columnar cells with inflammatory cell infiltration of the abundant stroma.

Through a MEDLINE search from 1970 to 1995 and a literature review by Hirata et al, ${ }^{11}$ we found 41 patients with juvenile polyposis affecting the stomach, including our three cases. Of these, 12 patients from 10 families had involvement solely of the stomach at presentation, corresponding to JPS. We reviewed the clinical features, gastric morphology, and histology of these 12 patients. Clinicopathological findings were compared to the remaining 29 patients with GJGP.

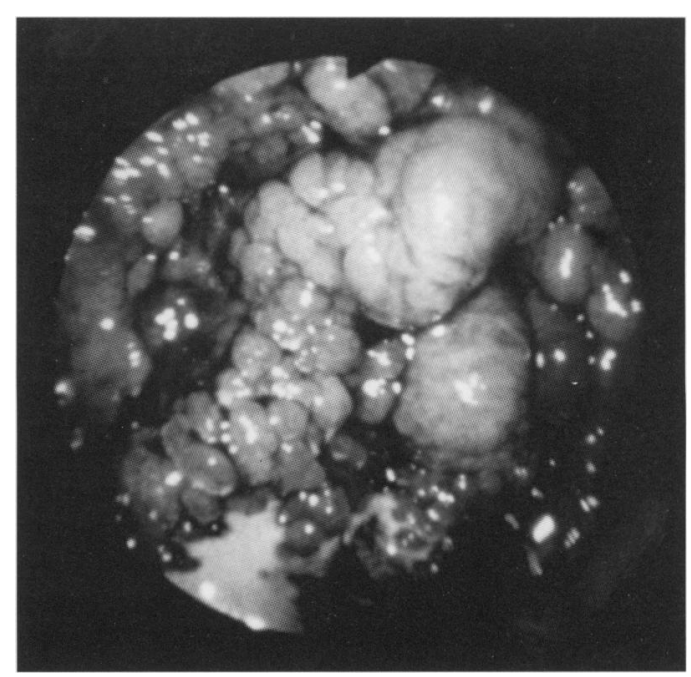

Figure 1 Gastroscopy showing multiple polypoid lesions with papillary surface in the stomach remnant (case 1). 

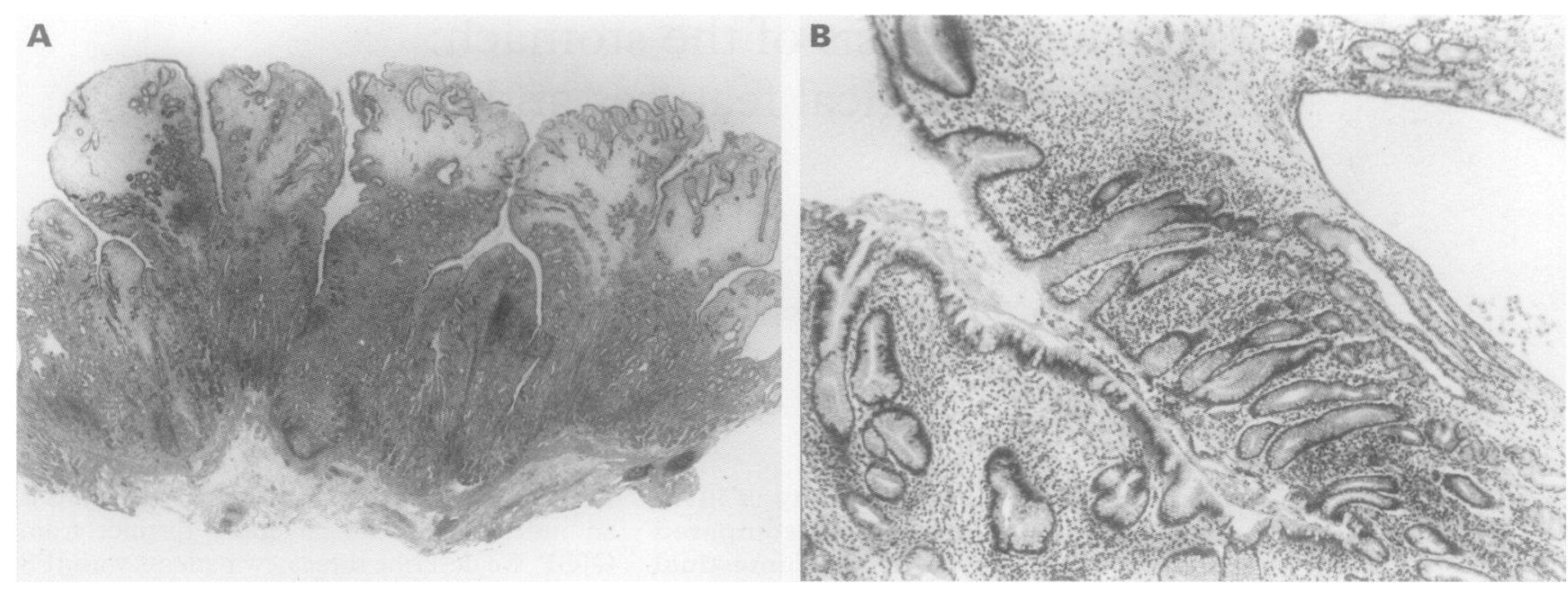

Figure 2 Gastric polyps from case 1 characterised by oedema and inflammatory cell infiltration of the stroma with cystic dilatation of the glands. (Haematoxylin and eosin, original magnifications $(A) \times 14,(B) \times 91$ ).

\section{Results \\ NEW CASES \\ Case 1}

A 31 year old man underwent an emergent operation of partial antral resection because of a perforated duodenal ulcer. The gastric antrum resected was covered by coarse granular mucosa, histologically composed of hyperplastic foveolar epithelium and focally cystic dilatation of the glands. Follow up gastroscopy performed two years later demonstrated multiple polypoid lesions in the stomach remnant. As these lesions gradually increased in number and size (fig 1), the patient experienced iron deficiency anaemia (haemoglobin $92 \mathrm{~g} / \mathrm{l}$ ) and hypoproteinaemia (serum total protein $57 \mathrm{~g} / \mathrm{l}$, serum albumin $40 \mathrm{~g} / \mathrm{l})$. There were no other abnormalities in the gastrointestinal tract, but the specimen obtained by endoscopic resection at age 38 years was typical of juvenile polyps (fig 2).

\section{Case 2}

A 19 year old woman was admitted to our hospital because of iron deficiency anaemia (haemoglobin $100 \mathrm{~g} / 1$ ) and hypoproteinaemia (serum total protein $38 \mathrm{~g} / 1$, serum albumin

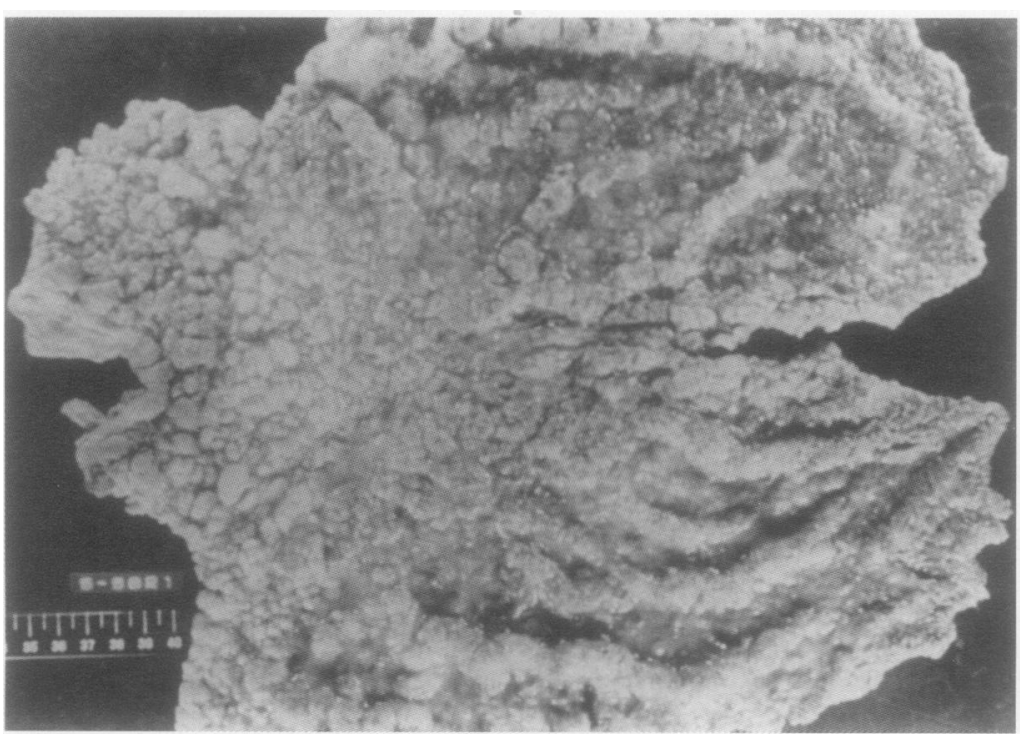

Figure 3 Resected specimen from case 2 revealing numerous diffuse small polyps throughout the entire stomach.
$28 \mathrm{~g} / \mathrm{l})$. Gastrointestinal examination revealed innumerable reddish polypoid lesions in the stomach alone. ${ }^{131}$ I-PVP test was $7.2 \%$ (normal $<1.5 \%$ ) and ${ }^{131} \mathrm{I}$-RISA test $4.5 \mathrm{~T}^{1 / 2}$ days (control 13 days). Medical treatment including total parenteral nutrition, antifibrinolysis treatment, and cimetidine administration was ineffective for protein losing gastropathy, therefore total gastrectomy was attempted. In the resected stomach there were numerous, diffuse, small, polypoid lesions (fig 3). Histological features were consistent with juvenile polyps, containing no cancerous tissue. Postoperative course was uneventful, and serum protein level returned to normal range.

\section{Case 3}

A 45 year old woman underwent partial gastrectomy for gastric polyps. The resected specimen showed multiple juvenile polyps in the gastric antrum with dysplastic foci. Juvenile polyps extended to the gastric fundus and appeared pedunculated. Iron deficiency anaemia (haemoglobin $75 \mathrm{~g} / \mathrm{l}$ ) and hypoproteinaemia (serum total protein $49 \mathrm{~g} / \mathrm{l}$, serum albumin $29 \mathrm{~g} / \mathrm{l})$ were advanced, and the ${ }^{125} \mathrm{I}$-PVP test was $2.7 \%$, therefore, the patient underwent total gastrectomy at age 65 years. In the resected specimen, we found giant polypoid lesions with papillary surface (fig 4). Histological examination showed a well to moderately differentiated adenocarcinoma limited to the mucosa, containing adenomatous epithelium with nuclear stratification in the juvenile polyps (fig 5). Since then, clinical manifestation improved, and we found no intestinal lesions during an observation period of 30 years.

\section{REVIEW OF THE LITERATURE}

There were 12 patients with JPS reported in the literature (two men and 10 women) (table 1). Age at initial diagnosis varied from 10 to 63 years (mean 32 years); four of the 12 patients were younger than 20 years of age. Seven patients had at least one family member with gastrointestinal polyposis. In addition, there was a family history of colorectal cancer in four patients and gastric cancer in two patients. No patient had a congenital abnormality. Anaemia was noted in nine patients (haemoglobin 


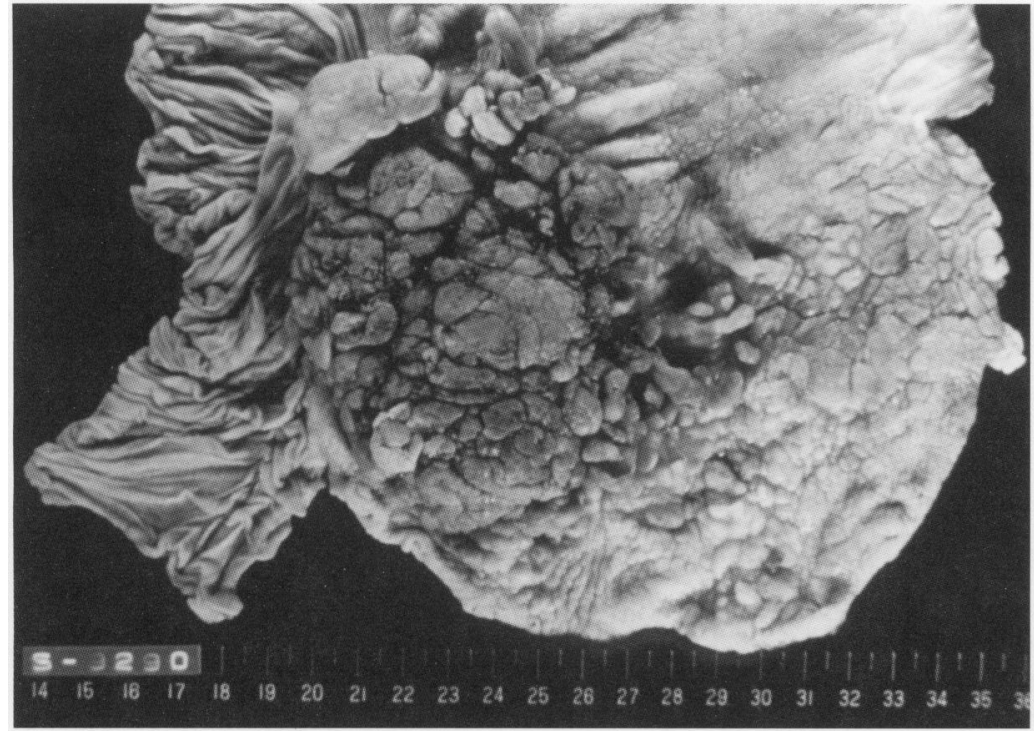

Figure 4 Resected specimen from case 3 revealing giant polypoid lesions in the stomach remnant.

$50-100 \mathrm{~g} / \mathrm{l})$ and hypoproteinaemia in seven (serum total protein $38-57 \mathrm{~g} / \mathrm{l}$ ).

The gastric antrum was invariably affected by juvenile polyps. Polypoid lesions in the antrum were more numerous, larger, and more pedunculated than those in the fundus. ${ }^{7}$ In four patients, neoplastic changes in the juvenile polyps were found, including adenoma, papillary adenocarcinoma, and well to moderately differentiated adenocarcinoma with adenomatous areas. Ten patients required gastrectomy for associated malignancy and/or uncontrolled hypoproteinaemia. During the observation period (mean age at final observation was 40 years), juvenile polyps developed in the colon in two patients, colon cancer was found in one patient, and colorectal adenomas were seen in one patient. All four of these patients had family members with juvenile polyposis.

\section{Comparison to GfGP with gastric involvement}

The 29 (10 female and 19 male) patients with GJGP involving the stomach ranged from one to 65 years of age (mean 28 years). Of these, 15 patients $(52 \%)$ had a family member with juvenile polyposis, and seven patients (24\%) developed gastric cancers. The 12 patients with JPS showed female preponderance compared with the GJGP patients (Fisher's exact probability test, $p=0.005)$. However, there was no difference in any other feature, including age at initial examination, family history, clinical presentation, and incidence of associated malignancy.

\section{Discussion}

Juvenile polyposis is categorised into several subtypes according to clinical features. McColl et $a l^{2}$ have termed the condition of colonic polyposis with juvenile polyps as juvenile polyposis coli (JPC). Sachatello et $a l^{3}$ separated GJGP from JPC when the stomach and/or small intestine also were involved. They also described a fatal form presenting with haemorrhage or protein losing enteropathy in infancy as juvenile polyposis of infancy, a more severe type of GJGP. ${ }^{4}$ Recently, the term juvenile polyposis, which includes these conditions, has been preferred because patients with JPC reportedly can also have extracolonic
A

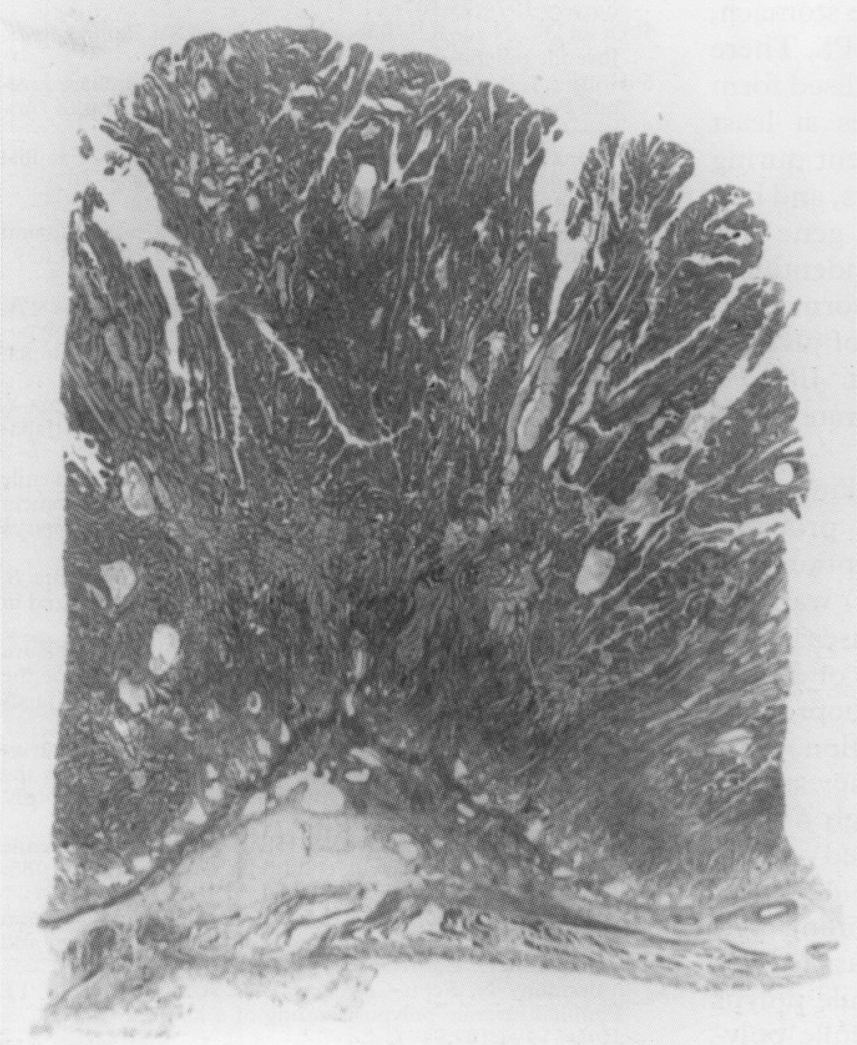

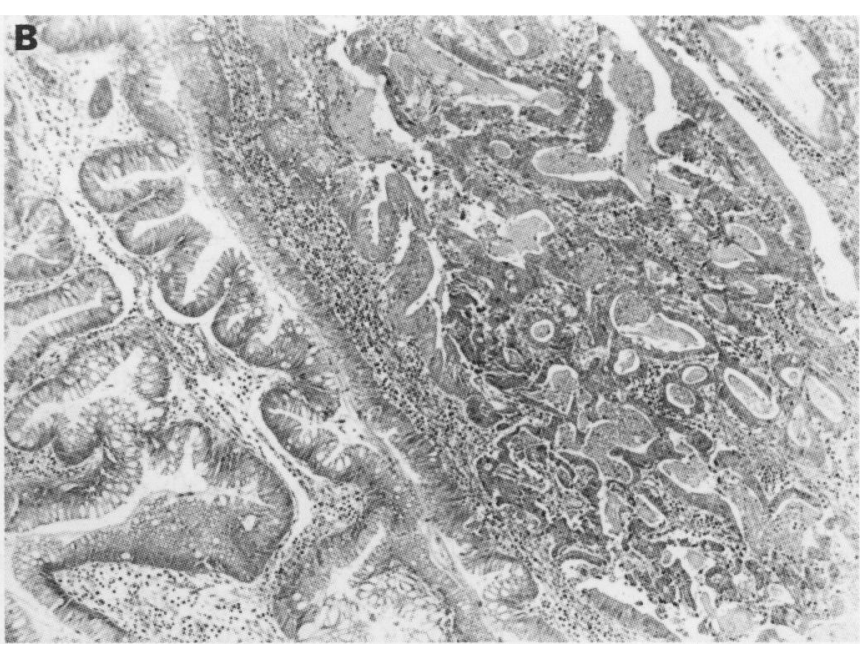

Figure 5 Histological examination of specimen from case 3 showing scattered areas of well to moderately differentiated adenocarcinoma limited to the mucosa in the juvenile polyps. (Haematoxylin and eosin, original magnification $(A) \times 5,(B) \times 91)$. 
Table 1 Summary of 12 patients with juvenile polyposis predominantly involving the stomach

\begin{tabular}{|c|c|c|c|c|c|c|c|c|}
\hline $\begin{array}{l}\text { Patient } \\
\text { No/sex } \\
\text { (reference) }\end{array}$ & $\begin{array}{l}\text { Age at } \\
\text { diagnosis } \\
\text { (years) }\end{array}$ & $\begin{array}{l}\text { Follow up } \\
\text { (years) }\end{array}$ & $\begin{array}{l}\text { Family } \\
\text { history }\end{array}$ & Anaemia & $\begin{array}{l}\text { Hypoprotein- } \\
\text { aemia }\end{array}$ & Gastric polyposis & $\begin{array}{l}\text { Gastric } \\
\text { neoplasia } \\
\text { (age)t }\end{array}$ & $\begin{array}{l}\text { Intestinal } \\
\text { lesion } \\
\text { (age) } t\end{array}$ \\
\hline $1 / \mathrm{male}^{\star}$ & 31 & 7 & - & Yes & Yes & Multiple & - & - \\
\hline $2 /$ female $^{\star}$ & 19 & 1 & - & Yes & Yes & Innumerable & - & - \\
\hline $3 /$ female $^{\star}$ & 45 & 30 & - & Yes & Yes & Innumerable & C/A (65) & - \\
\hline $4 /$ female $^{3}$ & 63 & 1 & $\mathbf{P}$ & Yes & Yes & Innumerable & - & JP (64) \\
\hline $5 / \mathrm{female}^{8}$ & 45 & 2 & $\mathrm{P} / \mathrm{C}$ & Yes & No & Multiple & - & C (47) \\
\hline $6 /$ female $^{8}$ & 10 & $1 \overline{7}$ & $\mathrm{P} / \mathrm{C}$ & Yes & No & Multiple & - & $\mathrm{JP}(27)$ \\
\hline $7 /$ female $^{7}$ & 13 & 7 & $\mathrm{P} / \mathrm{C}$ & Yes & Yes & Innumerable & - & - \\
\hline $8 /$ male $^{9}$ & 14 & 22 & $\mathrm{P} / \mathrm{C}$ & No & No & Innumerable & C (34) & A (36) \\
\hline $9 /$ female $^{12}$ & 21 & 1 & - & Yes & Yes & Innumerable & - & - \\
\hline $10 /$ female $^{6}$ & 41 & 6 & $\mathrm{P} / \mathrm{C}$ & Unknown & Unknown & Innumerable & - & - \\
\hline $11 /$ female $^{10}$ & 40 & 1 & $\mathrm{P} / \mathrm{C}$ & Yes & Yes & Innumerable & A $(40)$ & - \\
\hline $12 /$ female $^{13}$ & 32 & 1 & - & No & No & Multiple & C/A (32) & - \\
\hline
\end{tabular}

$\star$ Present study; †Age at diagnosis.

$\mathrm{P}$, polyposis; C, cancer; $\mathrm{A}$, adenoma; JP, juvenile polyp.

involvement. ${ }^{5}$ In a review of 272 cases of juvenile polyposis by Höfting et al, ${ }^{6}$ the most frequently affected site was colorectum $(98 \%)$, followed by stomach (14\%), jejunum and ileum $(6.5 \%)$, and duodenum $(2.3 \%)$. Solitary juvenile polyp mimics gastric hyperplastic polyp; however, the present cases obviously differ from hyperplastic polyps because they had more extensive and dense distributed polyps, presenting histological features of more abundant inflamed stroma and less foveolar hyperplasia than hyperplastic polyps.

Juvenile polyposis involving the stomach without intestinal polyps at presentation was termed juvenile polyposis of the stomach (JPS) by Watanabe et al. ${ }^{7}$ In the previous reports, ${ }^{38}$ two patients with JPS developed juvenile polyps in the colon, who were recategorised as GJGP. Therefore, we should consider that GJGP can present solely gastric involvement at the initial presentation. It may be why there was no difference in clinicopathological features between JPS and GJGP involving the stomach, except for female preponderance in JPS. There may be a possibility that JPS is a localised form of GJGP. However, our three cases at least manifested no extragastric involvement during the long term observations of 30 years, and had no hereditary trait. A causative gene for juvenile polyposis has not yet been identified, and factors other than genetic abnormalities may be related to the pathogenesis of juvenile polyposis. ${ }^{14}$ We would prefer that JPS be regarded as a clinical entity separate from GJGP.

In patients with JPS, the most striking clinical feature was anaemia $(89 \%)$, probably resulting from disturbed iron absorption and blood loss. Hypoproteinaemia (67\%) was also recognised frequently; Ménétrier disease can be excluded because of the presence of diffuse antral polyps. Most patients with hypoproteinaemia required gastrectomy. In addition, there may be an increased rate of malignancy associated with juvenile polyposis, although a juvenile polyp per se is categorised as a hamartoma. ${ }^{1}$ Höfting et $a l^{6}$ found 48 cases $(18 \%)$ of gastrointestinal cancer among 272 patients with juvenile polyposis. Jass et $a l^{15}$ found that 155 of 1009 (15\%) juvenile polyps removed from 80 patients with juvenile poly- posis were accompanied by dysplastic tissue. Among the 12 patients with JPS in this study, three developed gastric cancer with or without adenomatous area arising from juvenile polyps. Recent investigations strongly indicate a morphological sequence from hyperproliferative mucosa to adenocarcinoma, through mixed hyperplastic, juvenile, and adenomatous lesions. ${ }^{16} 17$

In conclusion, JPS has malignant potential and may be a separate entity from GJGP, which can present solely gastric involvement at initial presentation. Therefore, patients with JPS should be carefully followed up.

Morson BC. Some pecularities in the histology of intestinal polyps. Dis Colon Rectum 1962;5:337-44.

McColl I, Bussey HJR, Veale AMO. Juvenile polyposis coli. Proc $R$ Soc Med 1964;57:896-7.

3 Sachatello CR, Lickren JW, Grace JT. Generalized juvenile gastrointestinal polyposis. Gastroenterology 1970;58:699708 .

4 Sachatello CR, Hahn IS, Carrington CB. Juvenile gastrointestinal polyposis in a female infant: report of a case and review of the literature of a recently recognized syndrome. Surgery 1974;75:107-14.

5 Desai DC, Neale KF, Talbot IC, Hodgson SV, Phillips RKS Juvenile polyposis. Br $\mathcal{F}$ Surg 1995;82:14-7.

6 Höfting I, Pott G, Schrameyer B, Stolte M. Familiäre juvenile Polyposis mit vorwiegender Magenbeteiligung. $Z$ Gasnile Polyposis mit vorwiegen

7 Watanabe A, Nagashima H, Motoi M, Ogawa K. Familial juvenile polyposis of the stomach. Gastroenterology 1979;77: 148-51.

8 Stemper TJ, Kent TH, Summers RW. Juvenile polyposis and gastrointestinal carcinoma. Ann Intern Med 1975;83:639 46.

9 Morimoto Y, Nakao Y, Nagahara A, Tomoda J, Watanabe A, Nagashima $\mathrm{H}$, et al. Case report of familial juvenile polyposis of the stomach [Japanese]. $\mathcal{F p}$ $\mathcal{F}$ Gastroenterol 1986;83 $1376-81$.

10 Arakawa T, Ohida M, Tanabe S, Koizumi W, Yokoyama Y, Saigenji $\mathrm{K}$, et al. A case of juvenile gastric polyposis [Japanese]. Prog Dig Endosc 1993;43:154-7.

11 Hirata I, Adachi G, Hayashi K. Generalized juvenile gastrointestinal polyposis complicated with colon cancer and breast cancer: report of a case [Japanese]. Stomach Intestine 1993;28:1363-72.

12 Kimura M, Koguma M, Wada S, Anan Y, Yokoyama S, Minagawa $\mathrm{K}$, et al. A case of juvenile polyposis localized in the stomach. Ipn $\mathcal{F}$ Gastroenterol Surg 1988;21:689.

13 Shimono S, Takahashi N, Sakuyama T, Oonishi T, Ishikawa $\mathrm{T}$, Takamura S, et al. A case of juvenile polyposis of the T, Takamura $S$, et a nese]. Prog Dig Endosc 1994;44:119-22.

14 Leggett BA, Thomas LR, Knight N, Healey S, ChenevixTrench G, Searle J. Exclusion of APC and MCC as the gene defect in one family with familial juvenile polyposis. gene defect in one family with familia

15 Jass JR, Williams CB, Bussey HJR, Morson BC. Juvenile polyposis: a precancerous condition. Histopathology 1988, 13:619-30.

16 Sassatelli R, Bertoni G, Serra L, Bedogni G, Ponz De Leon $M$. Generalized juvenile polyposis with mixed pattern and gastric cancer. Gastroenterology 1993;104:910-15.

17 Subramony C, Scott-Conner CEH, Skelton D, Hall TJ Familial juvenile polyposis: study of a kindred. Am $₹ \mathrm{Clin}$ Pathol 1994;102:91-7. 